\title{
Existing Research and Standardization Suggestions on Evaluation Indicator System for Sustainable Rural Development
}

\author{
Yutong Wang ${ }^{1}$, Zhenyu Yun ${ }^{1,}$, Xiaolei $\mathrm{Ma}^{1}$, Yanlong Zhang ${ }^{2}$, Liangbing $\mathrm{Hu}^{1}$ \\ ${ }^{1}$ China National Institute of Standardization, Haidian District, Beijing 100191, China \\ ${ }^{2}$ Rural Development Institute Chinese Academy of Social Sciences, Dongcheng District, Beijing100732, China \\ "Corresponding author.Email: yunzy@cnis.ac.cn
}

\begin{abstract}
It was indicated in the report of the $19^{\text {th }} \mathrm{CPC}$ National Congress that rural revitalization is a major national strategy for the successful completion of building a moderately prosperous in all respects, and promoting sustainable rural development under the context of urban-rural integration is a defining feature of this strategy. Therefore, it is of great practical significance to study the evaluation indicator system for sustainable rural development in China and put it into practice under the current stage. Sustainable rural development is extremely inclusive as it not only embodies the overall deployment of the "Five-sphere Integrated Plan", but also involves the development of agriculture, rural areas and farmers, as well as relates to the final implementation of the rural revitalization strategy. Based on the existing research on the evaluation indicator system for sustainable rural development, this paper analyzes problems in the research and proposes suggestions on standardizing future research on this topic from five aspects of index acquisition, index source, index selection, index screening and evaluation organization.
\end{abstract}

Keywords: Rural sustainability, evaluation indicator system, existing research, standardization

\section{INTRODUCTION}

Under the current stage, rural revitalization is not limited to continuous improvement in rural living environment or sustainable development in a certain area over the construction of new socialist countryside; instead, it means promoting comprehensive, coordinated and sustainable development of rural economy, society and ecology to achieve the goal of comprehensive sustainable development of the countryside. Under the context of rural revitalization, evaluating the effectiveness of sustainable rural development is the basis for a comprehensive review of the deployment and practice of the rural revitalization strategy. How to objectively evaluate the current situation of rural sustainable development and further improve the effectiveness of rural revitalization is a theoretical and practical issue. An evaluation indicator system for sustainable rural development that is in line with the actual situation of China is needed. However, the existing evaluation indicator system for sustainable rural development in China is not standardized, incomparable and otherwise problematic. As an effective tool for establishing the best order, standardization has been applied in to all aspects of people's lives from industry in the beginning. It can support and guide the construction of a scientific, systematic and operable evaluation indicator system for sustainable rural development and contribute to better sustainable development of rural areas in China.

\section{CONNOTATION OF RURAL SUSTAINABLE DEVELOPMENT IN CHINA}

Sustainable rural development is extremely inclusive. In 1991, the concept of "sustainable agriculture and rural development" was first proposed in the Den Bosch Declaration and Agenda for Action on Sustainable Agriculture and Rural Development, and it meant continuously satisfying the basic need of current and future generations for agricultural products by managing and maintaining the basis of natural resources, supplemented by institutional reforms and technological innovation; it can effectively protect the genetic resources of arable land, water sources, animals and plants, and is technically appropriate, economically feasible, and socially acceptable. The goals of sustainable agriculture and rural development in China were clarified in China's Agenda 21, namely to maintain stable growth of agricultural productivity, to increase food production and ensure food safety, to develop rural economy, to increase farmers' income, to change rural poverty and backwardness, to protect and improve agroecological environment, and to make rational and sustainable use of natural resources, especially biological resources and renewable energy, so as to meet the year-toyear growing needs of national economic development and people's lives; in 2016, the United Nations issued the 2030 Agenda for Sustainable Development, and China issued the China's National Plan on Implementation of 2030 Agenda 
for Sustainable Development, in which China's sustainable development goals and policy framework were proposed, including messages about sustainable rural development; in 2018, the Rural Revitalization Strategic Planning (20182022) required that we should "adhere to green ecological orientation and promote sustainable agriculture and rural development". Over its evolution process, the sustainable rural development theory has been conceptually and internally deepened and expanded from economy and resources to politics, society, and ecology. The connotation of sustainable rural development includes:

\subsection{All-round Development of Human Beings is the Essence of Sustainable Rural Development}

Sustainable rural development pursues the unity of economic, social and ecological benefits. It is not only about the development of agricultural economy, but also about continuous improvement in the quality of life and income of farmers, population quality, consumption pattern, and people's living environment in order to achieve coordinated development of rural environment, population, economy and society. Therefore, sustainable rural development is essentially human development and multidimensional and comprehensive development of welfare level, quality of life, and state of rights between people and between generations.

\subsection{Sustainability is the Primary Feature of Sustainable Rural Development}

First of all, sustainability means that healthy and stable virtuous cycle and sustainable agriculture and rural development in the long run and in the interest of all rather than short-term or local economic growth or ups and downs in agriculture and rural development. Secondly, sustainable agriculture and rural development revisits development rather than simply deny it. This requires a steady increase in agricultural productivity, a gradual increase in grain output, guaranteed national food safety, and satisfaction of the growing need of people for agricultural and sideline products. For agriculture, it is not simple sustainable growth but high-quality development that matters, which means relying on scientific and technological progress and building a modern agricultural industry system, production system, and management system. At the same time, sustainability also requires high-quality farmers and improved rural living environment in order to promote highquality agriculture and rural development and enhance its endogenous ability. Last but not least, sustainability is not only an economic term, but also social, resource, and ecological terms that improved population quality, fair distribution of social wealth, sustainable use of resources, and ecological environment protection.

\subsection{System Coordination is the Basic Feature of Sustainable Rural Development}

Firstly, agriculture, rural and farmer development should be coordinated. Issues relating to agriculture, farmers and rural areas are always core issues in China's development. To address these issues, sustainable rural development is aimed at holistic agriculture and rural development. Sustained development means holistic and coordinated development that not only promotes sustainable development of agriculture and rural prosperity, but also helps farmers to become well-to-do and achieves moderate prosperity in all respects. Secondly, urban and rural development should be coordinated. Sustainable rural development is not confined to rural areas only; instead, it should allow for the whole picture of urban-rural integration. This requires promoting the flow of urban and rural factors, improving the system and mechanism for urban-rural integration, and effectively stimulating the vitality of agriculture and rural areas through urban-rural integration, based on the overall deployment of urban-rural integration. Thirdly, economic, social and ecological development should be coordinated. Agriculture and rural development must be pursued without sacrificing the environment and resources and must respect the ecological law, save resources and improve the ecological environment, and increase the efficiency of resource utilization. In China, agriculture and rural development is pursued on the basis of respecting the environmental and resource carrying capacities, maintaining the dynamic balance of the agricultural ecosystem, preserving the natural system by which humans live, and preventing environmental and ecological deterioration and other consequences caused by environmental pollution and overexploitation. Fourthly, production and life should be coordinated with resources and ecology. Sustainable development focuses on not only the overall macroeconomic development, but also welfare of farmers. To promote sustainable development requires improvement in production and living conditions of farmers and increase in their welfare, including the basic public services in urbanrural integration, improved population quality, and better infrastructure and people's living environment.

\subsection{Fairness is the Inherent Requirement of Sustainable Rural Development}

One of the core ideas of sustainable development is to pursue fairness among population, resources and environment, and this core idea is applied and embodied in the sustainable rural development under the rural context in China. It has two meanings under this context: Firstly, intrageneration fairness should be achieved by distributing limited resources fairly. In other words, unfair problems such as the widening gap of wealth over the process of agriculture and rural development should be solved, and gaps between urban and rural areas, regions, and industries should be gradually bridged to protect the poor and other vulnerable groups; secondly, inter-generational fairness 
should be achieved by meeting the needs of the current generation as much as possible while not depriving and impairing the ability of future generations to meet theirs.

\section{EXISTING RESEARCH ON EVALUATION INDICATOR SYSTEM FOR SUSTAINABLE RURAL DEVELOPMENT}

Many experts and scholars have studied the indicator system for sustainable rural development. Bingfu $\mathrm{Lu}$ and Yanli Zhou [1] built an indicator system for evaluating sustainable rural development capacity in China and an evaluation model that included 3 primary indicators, 9 secondary indicators and 20 tertiary indicators for rural economy, rural society and rural resources. They also cited relevant data to evaluate the sustainable rural development capacities of different provinces, cities, and autonomous regions in China; Jie Zhang [2] studied the current economic development of suburban and rural areas in Xinxiang City, Henan Province, with field research and analytic hierarchy process, and an indicator system for sustainable suburban and rural development that included 16 indicators in environment, resource, economy and society was initially built; based on a summary of the existing domestic and foreign research on the indicator system for sustainable urban development, Xiaopeng Li and Jing Wang [3] built an indicator system for suburban and rural development that included 16 indicators in economic, social, resource and environmental dimensions and summarized a comprehensive indicator system through weight analysis; considering the rural development in Suzhou City and Xiaogan City, Yuanmeng Ren [4] built an indicator system for sustainable rural development that included a total of 17 selected development indicators in terms of economy, society and resource environment to comprehensively evaluate the sustainable rural development level.

In summary, some scholars have studied the building of an evaluation indicator system for sustainable rural development from economic, social, resource and environmental perspectives and made weight analysis. In addition, other researchers tried to evaluate the sustainable rural development capacities of some regions in China. These previous academic efforts lay an important foundation for evaluating the sustainable rural development at the national level.

\section{MAJOR PROBLEMS IN THE RESEARCH ON EVALUATION INDICATOR SYSTEM FOR SUSTAINABLE RURAL DEVELOPMENT}

Building a scientific and reasonable evaluation indicator system to standardize development and evaluation is the prerequisite for promoting sustainable rural development. Although various evaluation indicator systems have been proposed to promote the evaluation of sustainable rural development, no normative document has been issued to encourage a consensus at the national level. In some places, there are still problems in the evaluation practice of sustainable rural development that prevent the full exertion of those evaluation indicator systems.

Firstly, the selected indicators are not distributed evenly. Sustainable rural development involves all aspects ranging from economy, society, people's livelihood, ecology to culture. The openness, uncertainty and dynamics of sustainable development makes it complex. Indicators to which high scores are assigned are preferred, while those associated with soft power and weaknesses are less selected. As a result, the evaluation indicator system is not complete. Secondly, the selected indicators are not focused enough. This is mainly reflected in the inclination to highly quantifiable indicators and the underestimation or ignorance of indicators that reflect development quality but are not quantifiable easily in some places. This malpractice in indicator weight setting makes the evaluation indicator system less scientific and diagnostic.

Thirdly, the established indicator system is not practical. In some places, the design of indicator system does not rely on any field research or allow for the actual situation. The designed indicators are too complicated or have little to do with realities. As a consequence, the established indicator system is neither convenient nor easy to collect objective and true data. These evaluation indicators are generally not standard, practicable or comparable. They are restricted by too many judgmental concepts and are not practical enough; descriptive indicators clearly out number normative ones, which makes the whole indicator system less pertinent and not applicable to the evaluation of sustainable development in specific fields.

The problems mentioned above are found in places where an evaluation indicator system has been built for sustainable rural development only. In fact, such an system is still absent in many other places. Clearly, the building of an evaluation indicator system remains a weakness in sustainable rural development as a whole. It is necessary to build an evaluation indicator system for sustainable rural development that is composed of representative, scientific, and practical important indicators selected scientifically and reasonably.

\section{SUGGESTIONS ON STANDARDIZATION OF RESEARCH ON EVALUATION INDICATOR SYSTEM FOR SUSTAINABLE RURAL DEVELOPMENT}

After analyzing the problems in the research on evaluation indicator system for sustainable rural development in China and considering the actual situation of China, the following suggestions are put forward for standardizing future research in this respect: 


\subsection{Improve the Index Acquisition Method and Enhance the Feasibility of Evaluation}

Acquiring indicators for evaluating sustainable rural development is a prerequisite for the building of a practical indicator system. Once the availability of indicators is neglected, it would be difficult to carry out evaluation and the value of the evaluation system will be greatly undermined. Therefore, in addition to sources of indicator data like existing management documents in agricultural and rural departments, statistical yearbooks (statistical departments), and official websites, it is necessary to guide all regions in collecting statistical data and conducting field research for evaluating sustainable rural development and in summarizing the evaluation indicators. The whole process should also include framework building, data collection and processing, and expert assessment to ensure that the selected indicator data is reliable, collectable, quantifiable, and comparable.

\subsection{Standardize Data Sources and Improve the Universality of Evaluation Indicators}

The research on the acquisition process of indicators used for building an evaluation indicator system shows that some indicators can be collected from many sources. However, different indicator sources provide different data values and ultimately varied evaluation results. Therefore, during the evaluation process of sustainable rural development at the national level, a document should be issued to standardize or unify sources and channels of data collection to produce more universal evaluation results and better reflect the actual situation of the evaluated target.

\subsection{Adopt A Scientific Selection Method and Build a Comprehensive and Hierarchical Evaluation Indicator System}

Sustainable rural development involves all aspects ranging from economy, society, ecology to resources, each of which is both independent and interconnected. Therefore, indicators of sustainable rural development should be selected from as many fields as possible theoretically and practically in order to ensure that the indicator system can reflect the sustainable rural development of a region in all aspects and from various angles; the indicator system should be divided into several subsystems each of which should be further broken down into different indicators to cover both macro and micro dimensions and to feature both comprehensiveness and classification. In this way, the evaluation indicators of sustainable rural development will be comprehensive and hierarchical.

\subsection{Screen Evaluation Indicators Reasonably and Produce More Scientific Evaluation Results}

After evaluation indicators are selected, screening is another important step. To screen the indicators, first of all, the screening principle should be defined. Next, the indicators should be screened reasonably and the weight coefficient should be determined. Finally, the chosen indicators are used for science-based evaluation of sustainable rural development. The evaluation indicators should not be so generalized as to result in information overlap or so uninformative as to cause information lapses.

\subsection{Organize Sustainable Development Evaluation Regularly and Improve Its Continuity}

The indicator system should be dynamic as it is built. Carrying out evaluation activities for sustainable rural development is a way to reveal sustainable rural development status from the evaluation result. In order to better reflect the trend of sustainable rural development in China or indifferent regions, the recommendation is to organize evaluation once a year regularly, plus appropriate adjustments in the design and selection of indicators based on the implementation process of sustainable rural development and specific rural conditions.

\section{CONCLUSION}

The evaluation of rural sustainable development plays an important and actual role in enriching the sustainable theory, drawing up and implement of strategy of sustainable agriculture and adjustment of policy and measure of agricultural and rural development. At present, the construction of evaluation index system is still the weak link of rural sustainable development, so it is necessary to use standardized means to enhance the representativeness, science and practicality of the evaluation index system of rural sustainable development, which is of great significance to promote the process of sustainable development in China.

\section{REFERENCES}

[1] Lu Bingfu, Zhou Yanli, Evaluation and empirical analysis of sustainable rural development capacity in China, Science Research Management. 30(S1) (2009):73-77.

[2] Zhang Jie, The construction of the index system and development strategy of suburban countryside's sustainable development - Take the suburban countryside of Xinxiang City for an example, Chinese Journal of 
Agricultural Resources and Regional Planning. 37(06) (2016):164-168.

[3] Li Xiaopeng, Wang Jing, Construction and evaluation of sustainable development planning index system of suburban rural areas, Chinese Journal of Agricultural Resources and Regional Planning. 38(01) (2017):129134.

[4] Ren Yuanmeng, Comparative Study on Sustainable Development of Typical Rural Cities in Eastern and Central China, Dissertation, Central China Normal University, 2019. 